\title{
三氟甲基季碳中心的合成进展
}

\author{
王守锋* 王文贵* \\ (济南大学化学化工学院 山东省氟化学化工材料重点实验室＼cjkstart济南 250022)
}

\begin{abstract}
摘要 三氟甲基是一个重要的含氟基团, 常被应用于药物和农药领域. 季碳中心是广泛存在于天然产物和合成药物中 的结构. 近年来, 构建含有三氟甲基季碳中心的分子得到了快速发展. 从直接三氟甲基化反应、新的合成砌块和新反应 的探索几个方面, 综述了近十年来合成三氟甲基季碳中心的研究进展.
\end{abstract}

关键词 三氟甲基; 季碳中心; 合成进展

\section{Recent Advances of the Construction of Trifluoromethylated Quaternary Carbon Center}

\author{
Wang, Shoufeng* Wang, Wengui* \\ (Shandong Provincial Key Laboratory of Fluorine Chemistry and Chemical Materials, School of Chemistry and Chemical \\ Engineering, University of Jinan, Jinan 250022)
}

\begin{abstract}
Trifluoromethyl is an important group, which is often used in pharmecuticals and agrochemicals. Quaternary carbon centers are widely existed in natural products and synthetic compounds. Recently, the construction of molecules containing trifluoromethylated quaternary carbon centers has been developed rapidly. Starting with direct trifluoromethylation, new synthons and new reactions, the research progress of the synthesis of trifluoromethylated quaternary carbon centers is reviewed.
\end{abstract}

Keywords trifluoromethyl; quaternary carbon center; research progress

三氟甲基具有强吸电子性、较大空间位阻、良好的 亲脂性以及稳定性, 将其引入有机分子中能够显著改变 目标分子的各种性能. 含三氟甲基 ${ }^{[1]}$ 药物和农药分子的 广泛使用促进了相应合成方法的迅速发展. 在现有方法

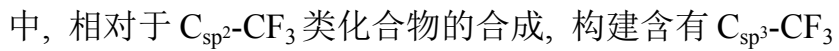
的发展相对缓慢. 同时, 季碳中心 ${ }^{[2]}$ 是广泛存在于天然 产物、药物和农药中的一种结构, 如抗癌药物紫杉醇中 就含有两个季碳中心. 季碳中心的构建一直是有机化学 中的一个挑战. 三氟甲基和季碳中心的结合, 则会产生 一个三氟甲基季碳中心. 由于氟原子的特殊性质, 这样 的结构具有强的刚性和独特的电性, 从而引起了合成化 学家的极大兴趣. 构建三氟甲基季碳中心主要有两个挑 战. 首先, 三氟甲基季碳中心的合成跟构建普通的季碳 中心一样, 由于季碳原子上同时连有四个含碳基团, 造 成空间上的拥挤. 构建三氟甲基季碳中心必须要克服空
间位阻. 其次, 如果通过负离子类型的反应构建三氟甲 基季碳中心, 则需要避免 $\beta$-脱氟效应. 近年来, 化学家 已经开发了多种方法, 实现三氟甲基季碳中心的合成. 将重点对近十年来构建三氟甲基季碳中心的反应研究 进展进行综述，包括直接三氟甲基化反应、三氟甲基砌 块的开发、新的反应体系和催化体系的研究等.

\section{1 直接三氟甲基化反应}

\section{1 亲电型三氟甲基试剂参与的反应}

直接向分子中引入三氟甲基来构建季碳中心，是一 条简捷高效的途径. 碳氢键的官能团化是近年来研究比 较多的领域. 将叔碳原子上的氢原子用三氟甲基取代, 会产生一个三氟甲基取代的季碳中心. 目前在这一类型 的反应中, 研究较多的是 $\beta$-酮酯的三氟甲基化反应. 所

\footnotetext{
* Corresponding authors. E-mail: chm_wangsf@ujn.edu.cn; chm_wangwg@ujn.edu.cn Received January 7, 2020; revised March 24, 2020; published online April 10, 2020. Project supported by the National Natural Science Foundation of China (No. 31972850) and the Shandong Provincial Key Research Program (No. 2019GSF108223).

国家自然科学基金(No.31972850)和山东省重点研发计划(No. 2019GSF108223)资助项目.
} 
用的三氟甲基化试剂多为亲电型试剂，如 Togni 试剂、 Umemoto 试剂等(Scheme 1).<smiles>O=C1OI(C(F)(F)F)c2ccccc21</smiles>

1
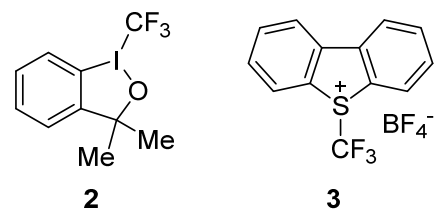

3
图式 1 常见亲电三氟甲基化试剂

Scheme 1 Common electrophilic trifluoromethylation agent

$\beta$-酮酯中的氢具有一定的酸性, 可以很容易地断 裂，进而和三氟甲基试剂反应，实现三氟甲基季碳中心 的构建. 2012 年, Gade 等 ${ }^{[3]}$ 报道了在手性 pincer 配体存 在下, 采用 1 作为三氟甲基化试剂, $\mathrm{Cu}(\mathrm{OTf})_{2}$ 催化的环 状 $\beta$-酮酯的三氟甲基化反应(Scheme 2). 对于五元环来 说, 可以高收率得到一个手性的三氟甲基季碳中心, ee 值最高可以达到 $99 \%$. 六元环底物采用 3 作为三氟甲基 来源, 并加入 ${ }^{i} \operatorname{Pr}_{2} \mathrm{NEt}$, 也可以很好的收率和对映选择性 得到三氟甲基季碳中心. 反应的产物可以进一步转化为 手性醇. 但是该反应只对环状酮酯适用, 链状酮酯在该 条件下并不适用. 2019 年, Cossío 和 Vallribera 等 ${ }^{[4]}$ 报道 了镧催化的环状 $\beta$-酮酯的不对称三氟甲基化反应 (Scheme 2). 同样, 在实验过程中, 作者发现五元环的 对映选择性明显优于六元环底物. 控制实验和理论计算 表明, 镧催化剂首先会和配体、 $\beta$-酮酯产生的烯醇络合, 得到的中间体再结合一个 Togni 试剂分子. 受到络合物 空间构型的限制，烯醇的 $R e$ 面进攻三氟甲基，发生一个 类似于 $\mathrm{S}_{\mathrm{N}} 2$ 的过程. 但是该反应并不能完全排除自由基 历程，这可能是导致 $e e$ 值不高的原因.

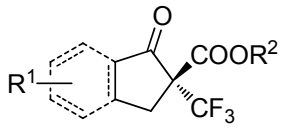

5

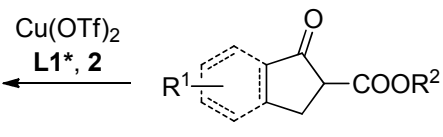

4

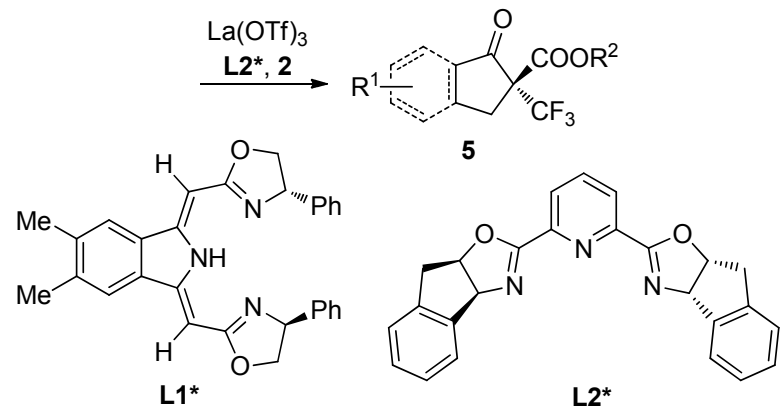

图式 2 金属催化的 $\beta$-酮酯的三氟甲基化反应

Scheme 2 Metal catalyzed trifluoromethylation of $\beta$-ketoesters

烯醇硅醚的三氟甲基化反应也可以用来构建三氟 甲基季碳中心. 2015 年, Togni 等 ${ }^{[5]}$ 报道了 Lewis 酸催化
的酯的烯醇硅醚和 2 的反应，链状底物和大部分环状底 物都能以很高的收率得到三氟甲基化产物. 五元环状底 物不加 Lewis 酸也可以发生反应，这可能是位阻较小、 电子云密度较高的缘故. 自由基阻止实验表明，该过程 是通过自由基历程进行的. Lewis 酸和 Togni 试剂的络合 可以促进单电子转移过程, 有利于三氟甲基自由基产 生. 该反应操作简便，可以实现克级制备.

2019 年, Katayev 等 ${ }^{[6]}$ 研究了环状酰胺和三氟甲基 试剂 2 在 $\mathrm{MgBr}_{2}$ 催化下的反应(Scheme 3). 该反应适用 范围广, 可以高收率、高选择性地实现环状酰胺的不对 称三氟甲基化反应. 三氟甲基试剂的空间位阻对反应选 择性有重要影响. 随着位阻的增大, 选择性逐渐降低. 基于实验和理论计算, 作者提出了一个单电子转移引发 的 $\mathrm{S}_{\mathrm{N}} 2$ 类型反应机理. 酰胺中一个质子转移到三氟甲基 试剂上，产生一个烯醇负离子并和镁络合. 该过程为反 应决速步，同时活化三氟甲基试剂，烯醇负离子会转移 一个电子给 2, 产生三氟甲基自由基. 在接下来的过程 中，由于受到络合物空间限制，烯醇部分、三氟甲基自 由基和试剂 2 剩余部分在空间上呈现近似直线排列. 三 氟甲基自由基同时和烯醇部分和试剂 2 的剩余部分作 用，呈平面型，而不是通常的四面体，这一过程类似于 $\mathrm{S}_{\mathrm{N}} 2$ 过程.<smiles></smiles><smiles>[Y]N1C(=O)C([R])(C(F)(F)F)c2cc[R1](C)cc21</smiles>

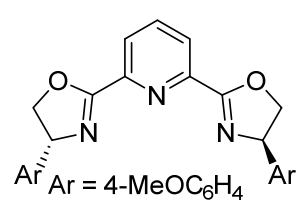
L3*<smiles>c1cc(C2=N[C@@H]3c4ccccc4CC[C@@H]3O2)nc(C2=N[C@@H]3c4ccccc4CC[C@H]3O2)c1</smiles><smiles>CCCC1(C)OI(C(F)(F)F)c2ccccc21</smiles>
$4^{*}$<smiles>C[CH+]CC1(C)OI(C)C1(C)C</smiles><smiles></smiles><smiles>COC(=O)N1C(=O)C(C)(C(F)(F)F)c2ccccc21</smiles>

图式 3 氧化吲哚的不对称三氟甲基化反应

Scheme 3 Asymmetric trifluoromethylation of oxindoles

除了羰基 $\alpha$-位的三氟甲基化，近年来其他含有三氟 甲基季碳中心化合物的合成方法也有报道. 2014 年, Togni 等 ${ }^{[7]}$ 对钒催化的硅基烯酮亚胺和三氟甲基试剂 $\mathbf{1}$ 的反应进行了研究 (Scheme 4). 在 $\mathrm{VO}$ (salen)配合物存在 下，可以较高收率得到 $\alpha$-三氟甲基取代腈类化合物，而 
且过程中不需要加入溶剂. 当配体上带有给电子、大体 积基团时，反应效果更好. 但采用手性 salen 配体时，仍 然得到消旋产物. 作者推测这一反应也是经过一个单电 子转移过程, 反应中产生了三氟甲基自由基.

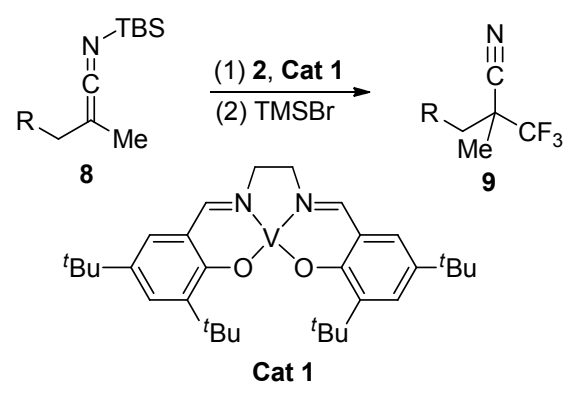

图式 4 硅基烯酮亚胺对称三氟甲基化反应

Scheme 4 Trifluoromethylation of silyl ketene imines

2016 年, 余达刚等 ${ }^{[8]}$ 报道了 $\mathrm{CO}_{2}$ 参与的烯丙基胺的 双官能团化反应. 在 $\left[\mathrm{Cu}\left(\mathrm{CH}_{3} \mathrm{CN}\right)_{4}\right] \mathrm{PF}_{6}$ 催化下, 以 1 作为 三氟甲基来源, 可以在烯丙基胺中碳碳双键的两个碳原 子上分别引入三氟甲基和含氧基团, 构建三氟甲基取代 的噁唑烷类化合物. 反应底物适用范围广, 产物可以进 一步衍生化, 得到多种结构的三氟甲基取代的含氮化合 物. 机理研究表明, 该过程中也发生了单电子转移. $\mathrm{Cu}(\mathrm{I})$ 和三氟甲基试剂 1 作用得到 $\mathrm{Cu}(\mathrm{II})$ 和三氟甲基自由 基. 底物和 $\mathrm{CO}_{2}$ 现场产生的氨基甲酸根负离子、 $\mathrm{Cu}(\mathrm{II})$ 发生络合, 环化, 最后和三氟甲基自由基作用得到产物.

\section{2 自由基型三氟甲基试剂参与的反应}

2015 年, Melchiorre 等 ${ }^{[9]}$ 报道了可见光催化的 $\beta$-酮 酯的三氟甲基化反应(Scheme 5). 该反应采用 $\mathrm{Cs}_{2} \mathrm{CO}_{3}$ 作 碱, $\mathrm{CF}_{3} \mathrm{I}$ 作为三氟甲基的来源, 金鸡纳碱衍生物作为手 性催化剂, 室温下通过可见光照射即可得到一个手性的 三氟甲基季碳中心, $e e$ 值最高可达 96\%. 作者认为一个 重要的中间体是烯醇负离子和 $\mathrm{CF}_{3} \mathrm{I}$ 形成的电子授受复 合物. 在该结构中, 三氟碘甲烷中的 $\mathrm{C}-\mathrm{I}$ 键被削弱, 可 见光照射下即可断裂产生三氟甲基自由基, 进而和烯醇 负离子反应, 实现三氟甲基季碳中心的构建. 而手性催 化剂的阳离子部分则通过和烯醇负离子的结合对反应 的 $e e$ 值产生影响. 2018 年, Yajima 等 ${ }^{[10]}$ 通过烯胺和全氟 烷基碘形成的电子授受复合物, 实现了可见光催化的醛 的 $\alpha$-位全氟烷基化反应，可以中等的收率得到三氟甲基 化的产物.

\section{3 其他试剂参与的反应}

2018 年, 刘应乐和杨义等 ${ }^{[11]}$ 通过吲哚林-2,3-二酮 和 $\mathrm{Ph}_{3} \mathrm{P}^{+} \mathrm{CF}_{2} \mathrm{COO}^{-}$的反应, 成功制备了 3-三氟甲基取代 的吲哚酮类化合物, 并对产物的生物活性进行了测试. 结果表明, 部分产物对前列腺癌细胞 PC-3 和乳腺癌细
胞 MCF-7 具有良好的抑制活性.

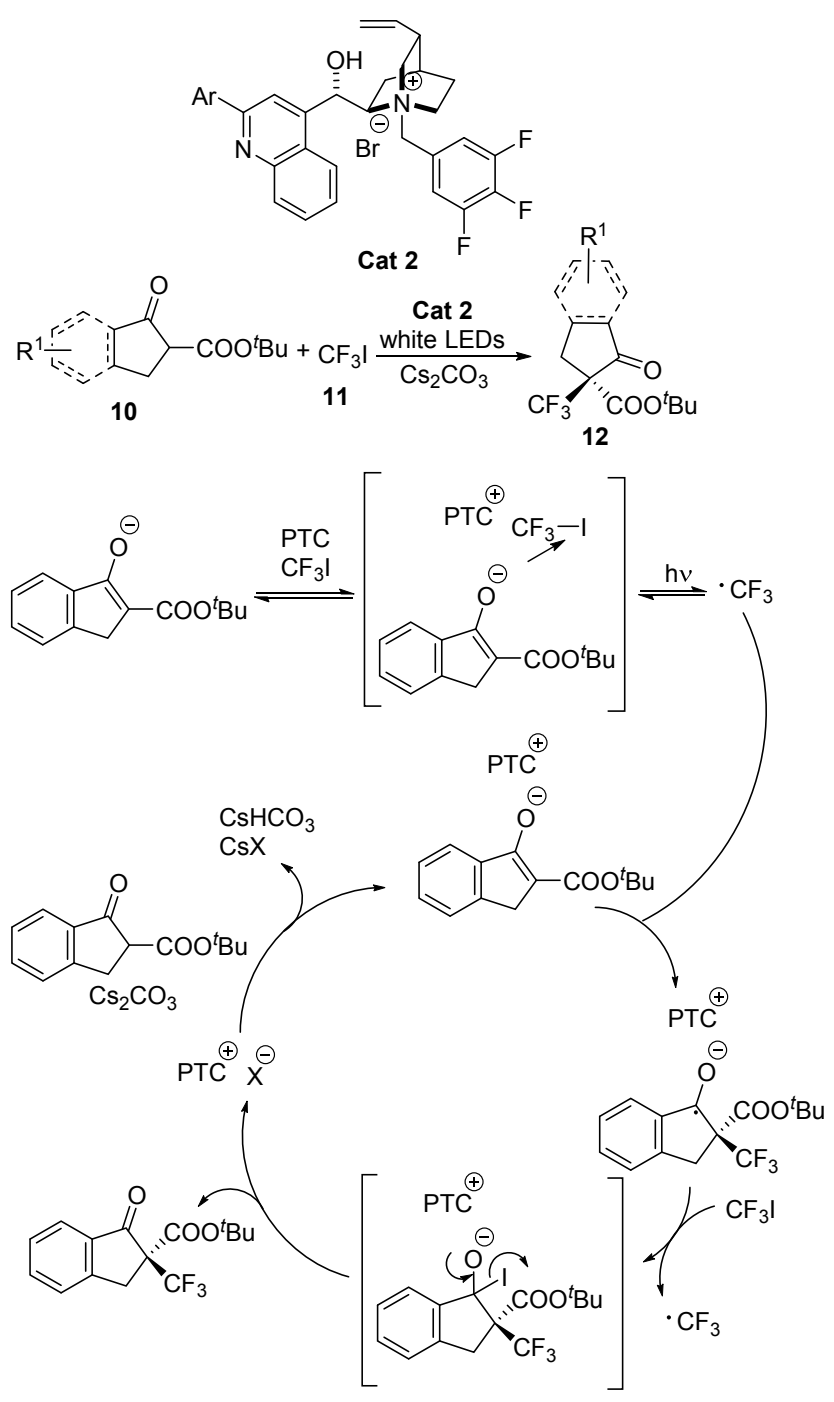

图式 5 可见光催化的的 $\beta$-酮酯的三氟甲基化反应 Scheme 5 Visible light-promoted trifluoromethylation of $\beta$-ketoesters

\section{2 三氟甲基砌块的反应}

\section{1 三氟甲基取代的亲核型试剂参与的反应}

由于三氟甲基的强吸电子性质，导致 $\alpha$-位的氢具有 一定的酸性, 容易发生碳氢键断裂, 形成碳负离子. 如 果在体系中存在一个亲电物种, 捕获该碳负离子, 则有 可能生成三氟甲基取代的季碳中心. 但这一过程中存在 的主要挑战是 $\beta$-脱氟效应. 生成的碳负离子很容易脱氟 得到其他副产物. 2009 年, Murahashi 等 ${ }^{[12]}$ 报道了首例过 渡金属催化的三氟甲基 $\alpha$-位碳氢键的官能团化反应 (Scheme 6). 在常用的碱, 如 DBU、 ${ }^{t} \mathrm{BuOK} 、 \mathrm{MeONa}$ 、 $\mathrm{Et}_{3} \mathrm{~N}$ 和 $\mathrm{BuNMe}_{3}^{+} \mathrm{OH}^{-}$存在下, 反应只能以很低的收率得 到产物, 或者没有目标产物生成. 当采用 $\left[\mathrm{IrH}_{5}\left(\mathrm{P}^{i} \mathrm{Pr}_{3}\right)_{2}\right]$ 或 $\left[\mathrm{Cp} * \mathrm{Ru}\left(\mathrm{PPh}_{3}\right)_{2}\right]$ 作为催化剂时, 反应可以顺利进行. 


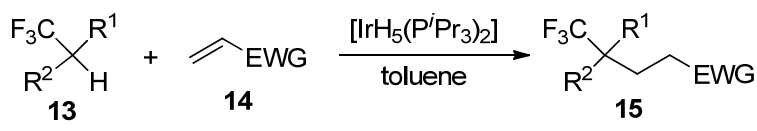

图式 6 铱催化的三氟甲基 $\alpha-\mathrm{C}-\mathrm{H}$ 的活化 Scheme 6 Activition of $\alpha-\mathrm{C}-\mathrm{H}$ trifluoromethyl group

作者认为, 在中性条件下, 三氟甲基取代的碳负离子会 和铱物种生成稳定的络合物, 从而避免了 $\beta$-脱氟反应发 生.

在进行控制实验过程中, 作者发现向体系中加入 $\mathrm{P}^{i} \mathrm{Pr}_{3}$ 作为催化剂, 也能以 $19 \%$ 的产率得到 Michael 加成 产物. 2013 年，郭勇、陈庆云和 Murahashi 等 ${ }^{[13]}$ 实现了 有机小分子催化的三氟甲基取代的亲核试剂对 $\alpha, \beta$-不饱 和酮的 Michael 加成反应(Scheme 7). 该反应以 $N, N-$ 二 甲基甲酰胺(DMF)作为溶剂, 用等物质的量的 1,5-二氮 杂二环 [5.4.0]十一烯-5 (DBU)、MeONa 或 $\mathrm{Et}_{3} \mathrm{~N}$ 作碱, 只 能得到 $45 \%$ 的收率. 当用中性的有机膦作为催化剂, 10 $\mathrm{mol} \%$ 时可得到较好的结果. 用XPhos 作为催化剂, 几乎 以定量的收率得到 Michael 加成产物, 同时 $\beta$-脱氟反应 得到了很好抑制。该反应底物适用范围广，对不饱和芳
香酮和脂肪酮都适用。作者认为, $\beta$-脱氟反应受到抑制 主要有两个原因: 一是有多个吸电子基团连接在该碳原 子上，使得碳负离子得到稳定；二是在反应过程中，碳 负离子和一个体积较大的季鏻盐的阳离子形成一个离 子对，有效地抑制了 $\beta$-脱氟.

2017 年, Foster 和 Stead 等 ${ }^{[14]}$ 报道了三氟甲基取代的 三酮哌嗪类化合物在手性胺存在下和 $\alpha, \beta$-不饱和酮的不 对称 Michael 加成反应(Scheme 8). 反应最高可以达到 $94 \%$ 的 ee 值, 经过重结晶进一步提高到 $98 \%$ 以上. 作者 提出，该反应首先生成三氟甲基取代的烯醇，由于共振 效应而得到稳定，从而抑制 $\beta$-脱氟. 有机胺夺取质子后 形成的正离子和烯醇负离子结合，在后续的反应过程中 影响产物选择性.

烯丙基化反应是有机化学中的一类重要反应. 在钯 催化的烯丙基化反应中, 通常需要一个亲核性物种和烯 丙基钯中间体反应. 如果将该反应用于三氟甲基取代的 亲核试剂，首先要克服 $\beta$-脱氟反应. 通常认为，烯丙基 钯物种亲电性很强, 在三氟甲基取代的碳负离子发生脱 氟反应之前就和该碳负离子结合. 此外，碳和钯之间形

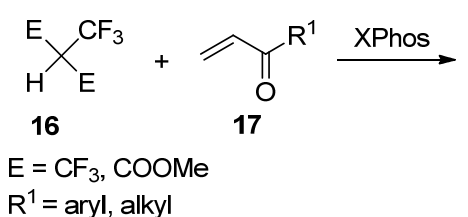<smiles>[R]C(=O)CCC(F)(F)C(F)(F)F</smiles>

18

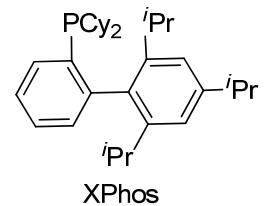

XPhos

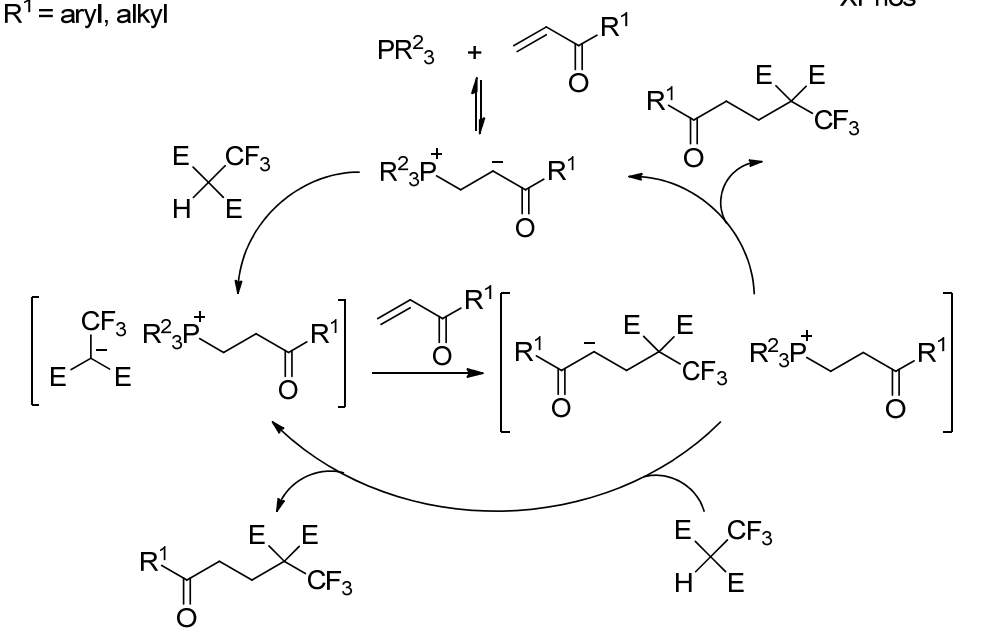

图式 7 有机小分子催化的 $\alpha$-三氟甲基酯和 $\alpha, \beta$-不饱和酮的 Michael 加成反应

Scheme 7 Organocatalytic Michael reaction of $\alpha$-trifluoromethyl esters and $\alpha, \beta$-unsaturated ketones<smiles>[R]N1C(=O)C(=O)N([13CH2])C(=O)C1C(F)(F)F</smiles><smiles>[R17]Nc1c(C(F)(F)F)n(Br)c(=O)c(=O)n1[18O]</smiles><smiles>[R]C(=O)CC[C@]1(C)NC(=O)C(=O)N([R17])C1=O</smiles>

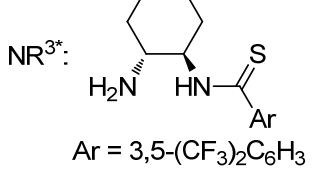

图式 8 有机小分子催化的三氟甲基取代杂环和 $\alpha, \beta$-不饱和酮的 Michael 加成反应 Scheme 8 Organocatalytic Michael reaction of trifluoromethylated heterocycles and $\alpha, \beta$-unsaturated ketones 
成的键具有较多的共价键性质, 使碳负离子上的负电荷 得到有效分散, 也可以避免 $\beta$-脱氟, 从而利于反应进行. 2013 年, 郭勇和陈庆云等 ${ }^{[15]}$ 报道了三氟甲基取代的酯 类化合物的烯丙基化反应(Scheme 9). 该反应底物适用 范围广, 反应条件温和, 在室温下即可发生, 烯丙基碳 酸酯和烯丙基苯均可用作烯丙基化试剂. 2015 年, 郭勇 和陈庆云等 ${ }^{[16]}$ 对含有三氟甲基取代的氢化噁唑类化合 物的烯丙基化反应进行了考察(Scheme 9). 该反应对于 多种结构的底物均适用, 得到含有三氟甲基取代的季碳 中心的杂环化合物. 通过对反应条件优化, 可以实现不 对称反应, ee 值最高为 74\%. 遗憾的是，该反应对大部 分底物的对映选择性很差, 部分几乎为零. 这也反映出 构建手性三氟甲基取代季碳中心的挑战性.<smiles></smiles>

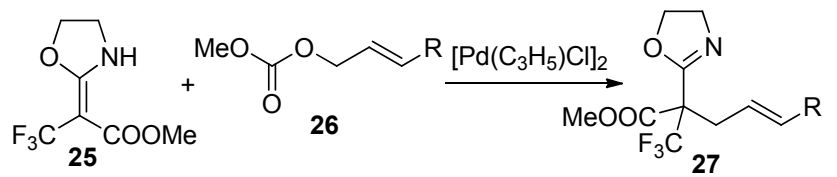

图式 9 钯催化的三氟甲基化合物的烯丙基化反应 Scheme 9 Pd-catalyzed allylation of trifluoromehtylated compounds

含三氟甲基的亲核试剂容易发生 $\beta$-脱氟反应得到 二氟代烯烃, 这是利用三氟甲基亲核试剂构建季碳中心 过程中需要避免的副反应. 但是在合适的条件下, 氟负 离子也可以对偕二氟烯烃加成, 得到三氟甲基取代的亲 核试剂. 2016 年, Loh 和冯超等 ${ }^{[17]}$ 报道了偕二氟烯烃在 $\mathrm{CsF}$ 存在下的烯丙基化反应(Scheme 10). 作者提出, 反 应顺利发生可能有如下几个有利因素：(1)在反应条件 下, 氟负离子对偕二氟烯烃的加成是可逆的; (2)碳碳键 的形成有利于反应进行; (3)反应可能的一种副产物是烯 丙基氟化产物, 该产物也可以重新离子化得到烯丙基钯 物种. 通过条件篮选, 以 $\mathrm{Pd}\left(\mathrm{CH}_{3} \mathrm{CN}\right)_{4}\left(\mathrm{BF}_{4}\right)_{2}$ 作为催化剂,

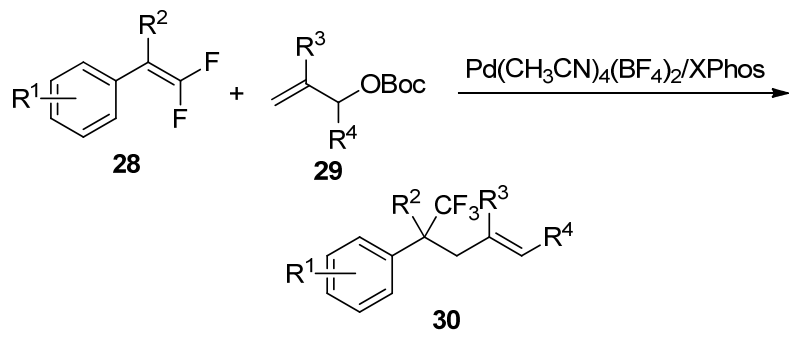

图式 $10 \mathrm{~F}^{-}$亲核加成诱导的烯丙基化反应 Scheme $10 \quad \mathrm{~F}^{-}$nucleophilic-addition-induced allylic alkylation
$\mathrm{XPhos}$ 作为配体，在 $\mathrm{CuF}_{2}$ 存在下，可以中等到优秀的收 率得到含三氟甲基季碳中心的化合物.

\section{2 三氟甲基取代的自由基型试剂参与的反应}

避免 $\beta$-脱氟反应的另外一条途径是改变反应历程, 不再产生碳负离子，而是通过其他活性物种，如自由基 等，实现三氟甲基取代季碳中心的构建. 可见光催化的 全氟烷基卤代物参与的单电子转移(SET)反应已经在有 机氟化学中得到广泛应用. 三氟甲基取代的叔卤代物的 反应，则可以在温和条件下合成三氟甲基取代的季碳中 心.

2013 年，陈庆云和郭勇等 ${ }^{[18]}$ 报道了可见光催化的 三氟甲基取代的叔溴代物和烯烃、炔烃的反应(Scheme 11). 在可见光催化下, 叔溴代物和烯烃反应得到一个环 状酰胺. 脂肪族烯烃和苯乙烯类化合物均可反应. 烯烃 上连有给电子取代基对反应更有利. 溴代物和炔烃的反 应则是发生原子转移自由基加成得到烯烃类产物。部分 产物表现出一定的农药活性，预示这类化合物在农药方 面具有一定的应用潜力. 2018 年, 陈庆云等 ${ }^{[19]}$ 报道了三 氟甲基叔溴代物和异腈的反应，得到了氮杂菲类化合物 (Scheme 11). 该反应底物适用范围广，带有不同取代基 的原料均能以高收率得到含有三氟甲基季碳中心的化 合物. 部分产物具有一定的杀虫、杀菌和除草活性.

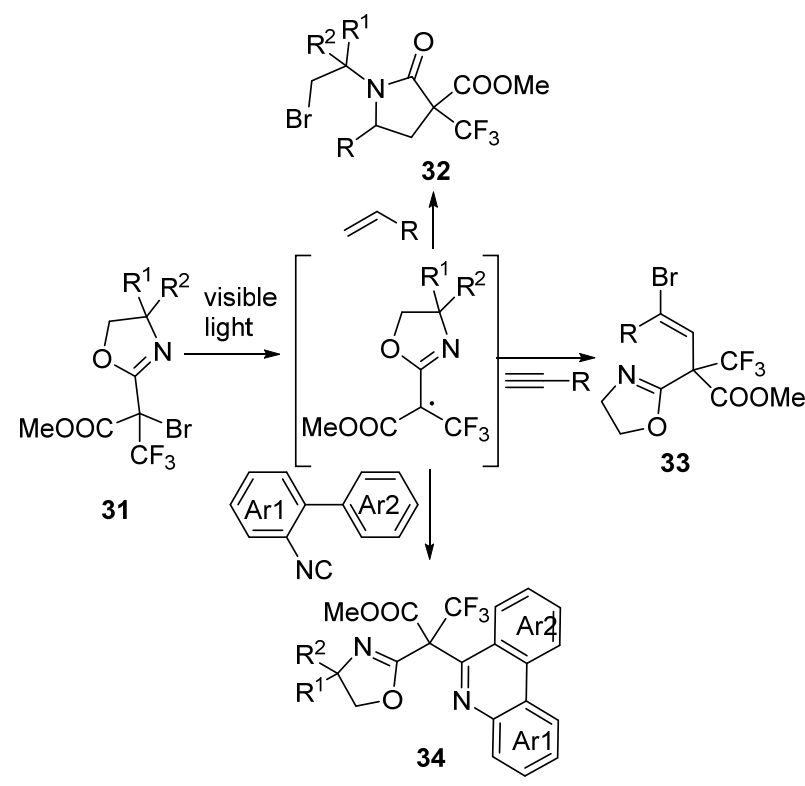

图式 11 可见光促进的三氟甲基叔溴代物的反应 Scheme 11 Visible light-promoted reactions of trifluoromethylated tertiary bromides

\section{3 三氟甲基取代的亲电型试剂参与的反应}

\subsubsection{Michael 加成反应}

三氟甲基取代的 $\alpha, \beta$-不饱和酮和硝基烯烃是非常有 用的合成子。这些化合物本身比较缺电子，容易发生 
Michael 加成反应. 结构中引入三氟甲基后, 电子云密 度进一步降低, 可以作为一个很好的 Michael 受体发生 反应.

2012 年, Shibata 等 ${ }^{[20]}$ 报道了金鸡纳碱衍生物催化 的氰根离子对三氟甲基取代的 $\alpha, \beta$-不饱和酮的 Michael 加成反应(Scheme 12). 在异丙醚中, 采用 $\mathrm{Cs}_{2} \mathrm{CO}_{3}$ 作碱, 现场产生的氰根离子可以和底物发生 1,4-加成, 得到含 有三氟甲基季碳中心的酮类化合物. 该反应的收率和对 映选择性都很高, ee 值最高可达 $96 \%$, 产物可以进一步 转化为含氮杂环化合物.

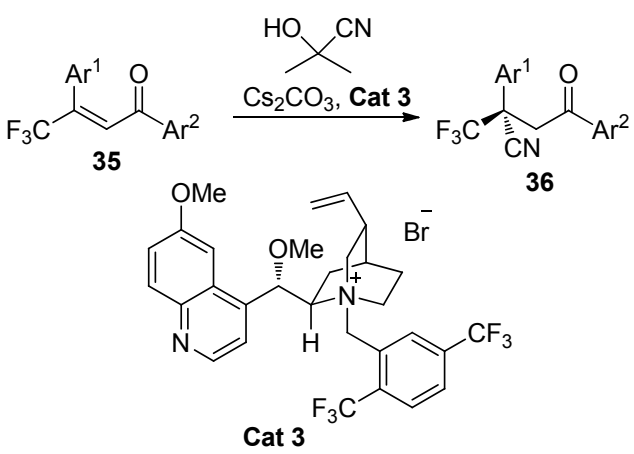

图式 12 有机小分子催化的氰根离子和 $\alpha, \beta$-不饱和酮的反应 Scheme 12 Organocatalytic reactions of $\mathrm{CN}^{-}$and $\alpha, \beta$-unsaturated ketones

2013 年, 该课题组 ${ }^{[21]}$ 又报道了金鸡纳碱衍生物催 化的硝基甲烷和三氟甲基取代的 $\alpha, \beta$-不饱和酮的 Michael 加成反应，也能得到很好的收率和立体选择性. 在该反应中, $20 \mathrm{~mol} \%$ 的催化剂给出较好的结果. 降低 催化剂用量虽然不会影响选择性, 但会使收率明显降低 (Scheme 13).
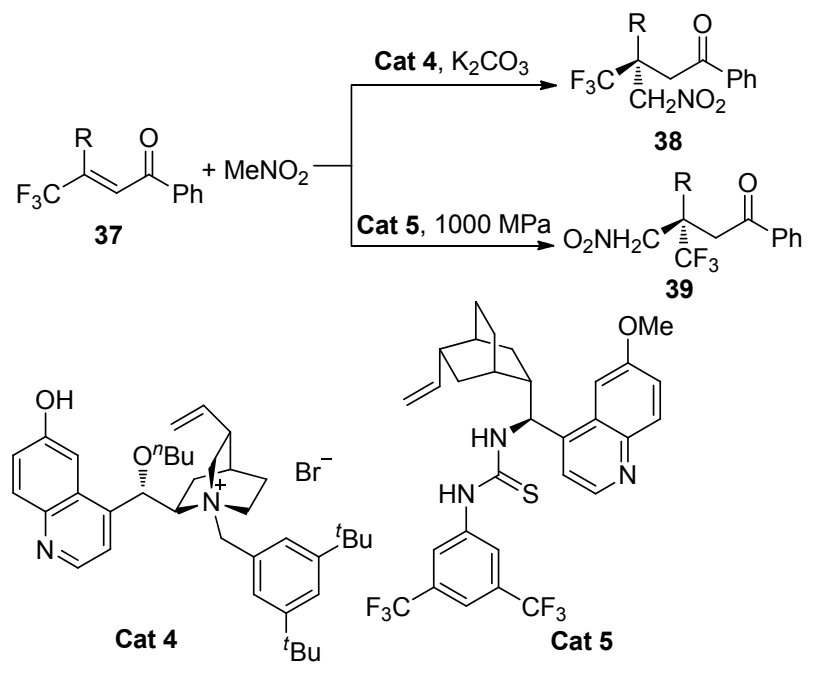

图式 13 有机小分子催化硝基甲烷和 $\alpha, \beta$-不饱和酮的不对称 反应

Scheme 13 Organocatalytic asymmetric Michael addition of nitromethane and $\alpha, \beta$-unsaturated ketones
2014 年, Kwiatkowski 等 ${ }^{[22]}$ 报道了高压下手性硫脲 催化硝基甲烷和三氟甲基取代的 $\alpha, \beta$-不饱和酮的反应. 在 $1000 \mathrm{MPa}$ 压力下, 催化剂用量降低到 $0.5 \sim 3 \mathrm{~mol} \%$, ee 值最高可达 98\% (Scheme 13).

2016 年, Blay 和 Pedro 等 ${ }^{[23]}$ 对端炔和三氟甲基取代 的 $\alpha, \beta$-不饱和酮的反应进行了考察(Scheme 14). 在 1.5 equiv. $\mathrm{Et}_{2} \mathrm{Zn}$ 和 $2.5 \mathrm{~mol} \%$ 手性 BINOL 配体存在下，可以 中等到优秀的收率和对映选择性得到相应产物. 增加 $\alpha, \beta$-不饱和酮上取代基的体积，有利于选择性的提高. 产物可以进一步转化为 $4 H$-吡喃类化合物.

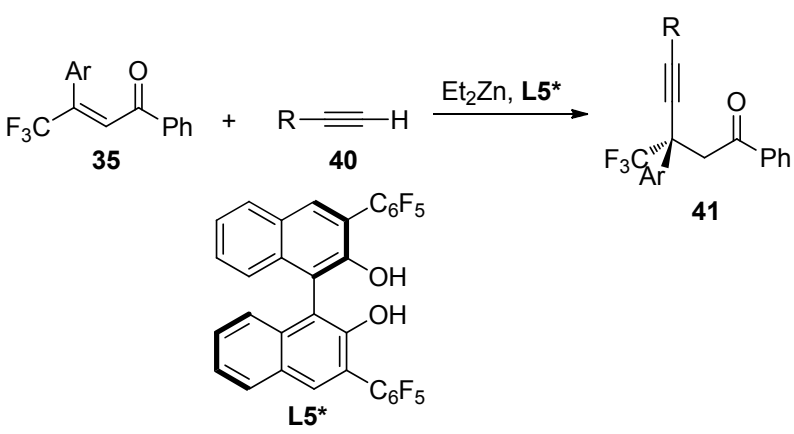

图式 14 末端炔烃和 $\beta$-芳基- $\beta$-三氟甲基不饱和酮的不对称反 应

Scheme 14 Enantioselective reaction of terminal alkynes and $\beta$-aryl- $\beta$-trifluoromethyl enones

三氟甲基取代的硝基烯烃也是一类非常有用的合 成子. 2013 年，贾义霞等 ${ }^{[24]}$ 报道了 $\mathrm{Ni}$ 催化吲哚类化合物 和三氟甲基取代的硝基烯烃的 Michael 类型的芳基化反 应(Scheme 15). 由于吲哚的 3-位电子云密度较大, 可以 和缺电子双键发生加成反应，采用 $\mathrm{Ni}\left(\mathrm{ClO}_{4}\right)_{2} \cdot 6 \mathrm{H}_{2} \mathrm{O} /$ bisoxazoline 作为催化体系, 最高可获得 $96 \%$ 的 ee 值. 吲 哚环上引入吸电子取代基和增加空间位阻都不利于反

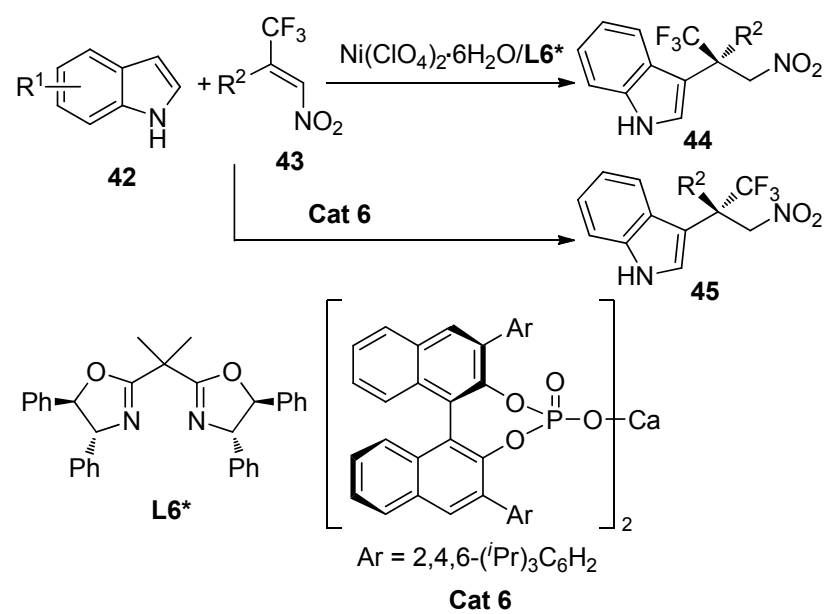

图式 15 镍催化的吲哚和三氟甲基硝基烯烃的反应

Scheme 15 Ni-catalyzed reactions of indoles and trifluomethylated nitroalkenes 
应进行. 控制实验表明, 氟原子的取代在这一反应过程 中具有重要影响. 当采用结构类似的非氟代化合物进行 反应时, 产率只有中等, ee 值降低到 33\%. 2019 年, Akiyama 等 ${ }^{[25]}$ 采用手性磷酸钻盐作为催化剂对这一反 应进行了改进(Scheme 15). 反应底物适用范围广, 选择 性最高可以达到 $98 \%$. 同时, 在该条件下, 反应时间缩 短, 条件更温和.

羰基化合物由于 $\alpha-\mathrm{H}$ 的酸性, 也是一类很好的亲核 试剂. 2014 年, 刘全忠等 ${ }^{[26]}$ 报道了丙二酸二酯对三氟甲 基取代的硝基烯烃的 Michael 加成反应(Scheme 16). 采 用 $20 \mathrm{~mol} \%$ 手性硫艮作为催化剂, $\mathrm{NaOAc}$ 作碱, 室温下 即可以较高的收率和对映选择性得到相应产物. 烯烃分 子中吲哚部分取代基的位置和氮原子上保护基的种类 都会对反应产生影响. 4-位有取代基时该反应不能发生. 同时, Boc 保护的底物反应结果优于 Ts 保护的底物. 同 年, 王锐和许兆青等 ${ }^{[27]}$ 报道了手性硫腿催化的烯基氧 化吲哚类化合物和三氟甲基取代的硝基烯烃的反应. 该 反应可以获得高的非对映选择性 $(d r>20: 1)$ 和对映选 择性, 大部分产物可以达到 $99 \%$ 的 $e e$ 值. 如果采用具有 相反手性的催化剂, 也可以 $98 \% \sim 99 \% e e$ 得到具有相反 构型的产物. 氧化吲哚部分氮原子上如果没有取代基, 则反应不能发生. 2019 年, Song 等 ${ }^{[28]}$ 报道了小分子催化 的丙二酸二硫醇酯和三氟甲基取代硝基烯烃的不对称 Michael 加成反应(Scheme 16). 作者发现, 在有机溶剂 如甲苯、二氯甲烷中, 反应虽然可以获得优秀的对映选 择性, 但是转化率较低. 如果以饱和食盐水作为溶剂, 甲苯作为共溶剂, 反应的收率和对映选择性都会提高. 在该过程中, 硫原子的存在是非常重要的, 换为氧原子 则不发生反应.

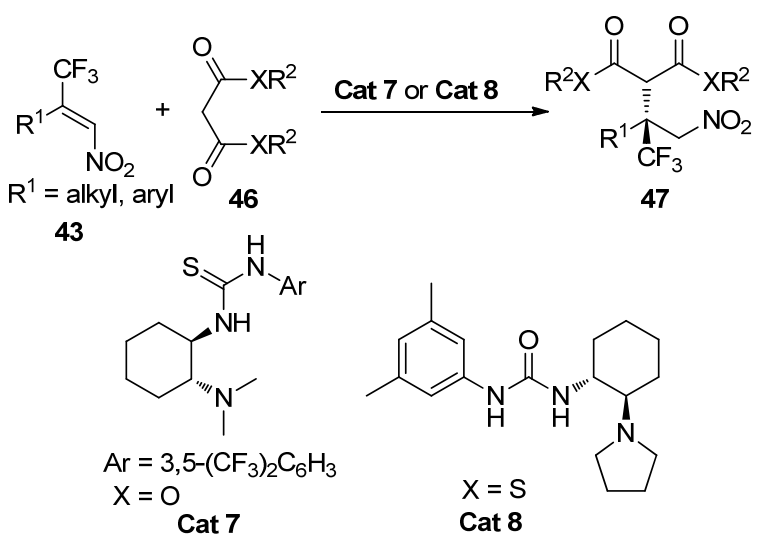

图式 16 丙二酸酯和三氟甲基硝基烯烃的不对称反应 Scheme 16 Enantioselective Michael additions of malonates and trifluoromethylated nitroalkenes

甲基芳基酮也可以用作亲核试剂. 2016 年, $\mathrm{Fu}$ 等 ${ }^{[29]}$ 对 $\mathrm{Ni}$ /bisoxazoline 体系催化 2-乙酰基氮杂环类化合物和 三氟甲基取代硝基烯烃的 Michael 加成反应进行了报道.
研究表明, 该反应底物适用范围广, 在 $0{ }^{\circ} \mathrm{C}$ 下可以得到 很高的对映选择性, ee 值可达 99\%. 2017 年, 宋毛平和 龚军芳等 ${ }^{[30 a]}$ 报道了室温下高选择性的 $\mathrm{Co} /$ /imidazolineoxazoline)体系催化乙酰基杂环的反应. 单环底物可以 得到中等到优秀的收率, 并环底物的收率和选择性则较 低. 在两篇文章中, 作者都认为, 催化剂中的金属离子 同时和手性配体、三氟甲基取代硝基烯烃和酮的烯醇式 配位，拉近了烯醇和硝基烯烃的距离，并对亲核进攻的 选择性产生影响. 申永存等 ${ }^{[30 b]}$ 报道了有机小分子催化 的 5-吡唑啉酮和三氟甲基取代硝基烯烃的 Michael 加成 反应. 以 $\mathrm{NaOH}$ 作为碱, $\mathrm{CH}_{2} \mathrm{Cl}_{2}$ 作为溶剂, 反应在室温 下即可获得中等以上的收率和最高 $97 \%$ 的 $e e$ 值.

\subsection{2 环加成反应}

环加成反应是有机化学中的一类重要的反应, 可以 方便快速地合成结构多样的环状化合物. 通过设计合适 的底物结构可以实现三氟甲基取代的季碳中心的构建. 2013 年, Nikolaev 和 Davies 等 ${ }^{[31]}$ 报道了三氟甲基取代的 $\alpha$-重氮酯、 $\alpha$-重氮酮和取代呋喃类化合物在铑催化下的 反应(Scheme 17). 作者发现, 向重氮邻位的碳原子上引 入取代基后，会抑制现场产生的卡宾中间体和呋喃的分 子间反应. 相反, 分子内反应更为有利, 会产生一个环 丙烯中间体和三氟甲基取代呋喃，环丙烯中间体则可以 被呋喃捕获, 得到 $[4+2]$ 环加成的产物. 催化剂的溶解 性对产物有重要影响. 当采用溶解性较差的 $\mathrm{Rh}_{2}(\mathrm{OAc})_{4}$ 作为催化剂时，同时得到三氟甲基取代呋喃和 [4+2]环 加成产物. 当采用溶解性较好的催化剂, 如 $\mathrm{Rh}_{2}(\mathrm{Ooct})_{4}$ 和 $\mathrm{Rh}_{2}(S \text {-DOSP })_{4}$ 时, 则只能观察到生成三氟甲基取代 的呋喃; 如果降低催化剂的用量, 也可以观察到混合物 的生成. 说明体系中催化剂的量对反应过程具有重要影 响. 催化剂的量较大时, 产生的环丙烯中间体会快速转 化为呋喃, 而不会被呋喃捕获.

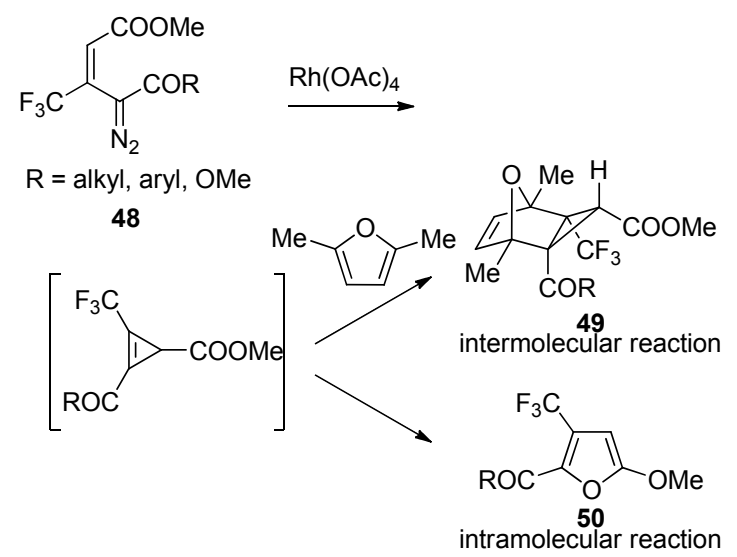

图式 17 铑催化的三氟甲基重氮化合物的反应 Scheme 17 Rh-catalyzed reactions of trifluoromethylated vinyldiazocarbonyl compounds 
1,3-偶极子是一类常用的用作环加成反应的化合 物, 容易和不饱和键发生 $[3+2]$ 环加成. 2015 年, Loska 等 ${ }^{[32]}$ 报道了一例咪唑 $N$-氧化物和三氟甲基取代烯烃的 环加成反应. 产物经过重排等一系列反应, 得到取代的 咪唑类化合物. 施敏等 ${ }^{[33]}$ 对 3-异硫氰基氧化吲哚和三氟 甲基取代的丁烯二酸酯的 $[3+2]$ 反应进行了考察. 采用 手性的金鸡纳碱类化合物作为催化剂, 可以很高的选择 性得到环加成的产物. 溶剂对反应的选择性有很大影 响, 在甲苯中反应可以顺利进行. 用乙腈作为溶剂时, 非对映选择性会反转, ee 值也会剧烈下降. 采用相反构 型的丁烯二酸酯均能得到一致的结果, 因为在体系中存 在两种构型的互变.

2-(三甲基硅甲基)烯丙基乙酸酯常被用作 1,3-偶极 子的前体参与环加成反应. 2015 年, Trost 等 ${ }^{[34]}$ 对钯催化 的 2-(三甲基硅甲基)烯丙基乙酸酯和三氟甲基取代烯烃 的 $[3+2]$ 反应进行了考察(Scheme 18). 在以前的报道中, 烯烃部分通常会连有一个不饱和的吸电子基团, 这里作 者则用三氟甲基来活化烯烃. 反应能够以中等到优秀的 收率得到预期产物. 但增加烯烃取代基的位阻时，反应 收率会有明显降低，同时通过氟谱观察到反应体系中有 $\beta$-脱氟产物, 这说明了反应不是协同过程, 而是分步进 行的. 向 2-(三甲基硅甲基)烯丙基乙酸酯中引入一个可 以稳定负电荷的炔基后, 可以 $91 \%$ 的收率得到环加成产 物. 该反应适用范围广, 对于二取代和三取代的烯烃都 适用. 同时, 分子内如果同时存在碳碳双键和碳碳参键, 反应发生在双键处. 如果分子内存在共轭的双键, 则反 应在三氟甲基取代的双键上发生.

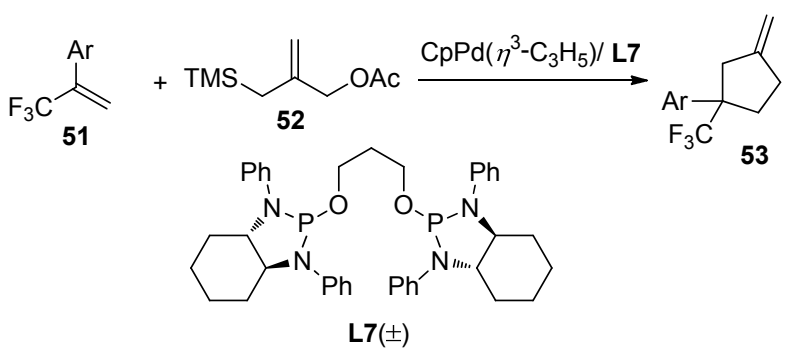

图式 18 钯催化的三氟甲基活化烯烃的环加成反应

Scheme 18 Pd-catalyzed cycloadditions of alkenes activated by trifluoromethyl group

亚胺酯在碱性条件下, 可作为 1,3-偶极子的前体和 不饱和键进行 [3+2]环加成反应. 2016 年, 张俊良等 ${ }^{[35]}$ 报道了亚胺酯和三氟甲基取代的 $\alpha, \beta$-不饱和酮的反应 (Scheme 19). 以 $\left[\mathrm{Cu}\left(\mathrm{CH}_{3} \mathrm{CN}\right)_{4}\right] \mathrm{ClO}_{4} / \mathrm{Ming}-\mathrm{Phos}$ 作为催化 体系, THF/MTBE 作溶剂, 仅需要 $50 \mathrm{~mol} \%$ 的 $\mathrm{Cs}_{2} \mathrm{CO}_{3}$ 作 碱, 即可引发反应, 以高的收率和对映选择性得到多取 代的四氢吡咯衍生物. 但是当把 $\alpha, \beta$-不饱和酮羰基一侧 的芳基换为烷基后，反应则不能发生. 类似的反应体系 也可应用于三氟甲基取代的 $\alpha, \beta$-不饱和酯的反应. 2017 年，张俊良等 ${ }^{[36]}$ 报道了 $\left[\mathrm{Cu}\left(\mathrm{CH}_{3} \mathrm{CN}\right)_{4}\right] \mathrm{BF}_{4} / \mathrm{MingPhos}$ 作 为催化体系，亚胺酯和三氟甲基取代的 $\alpha, \beta$-不饱和酯的 $[3+2]$ 环加成反应，反应产物的 $e e$ 值最高可达 $99 \%$ (Scheme 19). 对于 (Z)-构型的底物可以顺利反应, 但是 采用 $(E)$ 构型的底物时, 则只能得到消旋的产物. 如果把 配体中氮原子上的氢用甲基取代，反应的收率和对映选 择性都会降低, 说明 $\mathrm{N}-\mathrm{H}$ 在反应过程中起着重要作用,

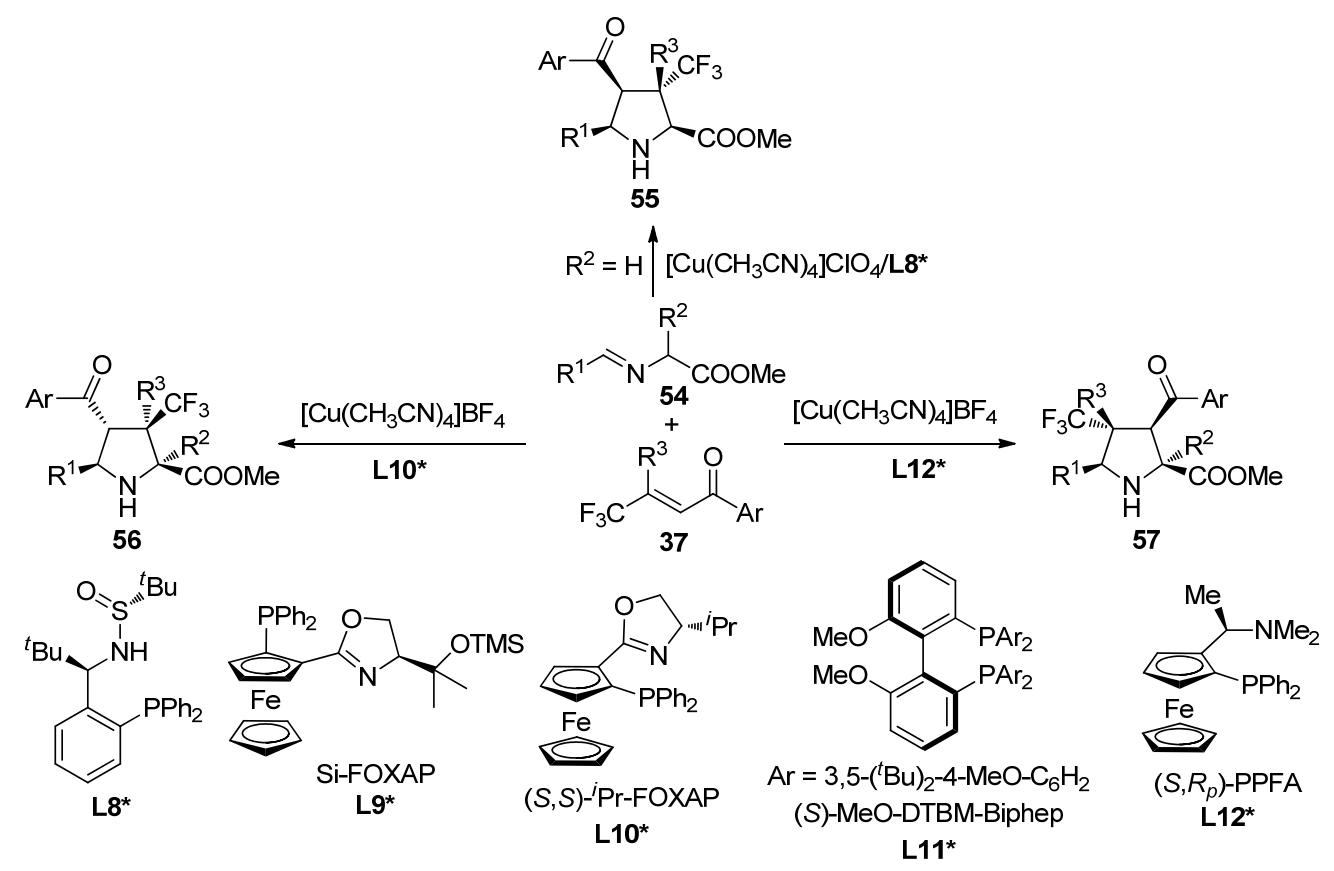

图式 19 亚胺酯和三氟甲基取代的 $\alpha, \beta$-不饱和酮的 $[3+2]$ 环加成反应

Scheme 19 Cycloadditions of iminoesters and trifluoromethylated $\alpha, \beta$-unsaturated ketones 
该作用可能是通过氢键稳定产生的烯醇负离子，抑制了 $\beta$-脱氟反应的发生.

张俊良等 ${ }^{[37]}$ 在研究中发现, 采用轴手性配体 $(S)$ MeO-DTBM-Biphep 和 $\left[\mathrm{Cu}\left(\mathrm{CH}_{3} \mathrm{CN}\right)_{4}\right] \mathrm{BF}_{4}$ 作为催化体系, 可以高效地催化亚胺酯和 $\beta$-三氟甲基取代的 $\alpha, \beta$-不饱和 酮的环加成反应, 得到的产物为 exo 构型, 这与采用 Ming-Phos 作为配体时恰好相反. 反应的非对映选择性 和对映选择性都很好. 通过该反应, 可以一次实现四个 手性中心的构建, 其中有一个是三氟甲基取代的季碳中 心.

在后来的研究过程中, 张俊良等 ${ }^{[38]}$ 发现, 在亚胺酯 和 $\beta$-三氟甲基取代的 $\alpha, \beta$-不饱和酮的环加成反应中, 配 体不仅会影响三氟甲基季碳中心的构型，也会影响反应 的区域选择性(Scheme 17). 采用相同的金属催化剂 $\left[\mathrm{Cu}\left(\mathrm{CH}_{3} \mathrm{CN}\right)_{4}\right] \mathrm{BF}_{4}$, 当用 $(S, S)-{ }^{i} \mathrm{Pr}-\mathrm{FOXAP}$ 作为配体时, 产物中存在两个连续的季碳中心. 如果采用 $\left(S, R_{\mathrm{p}}\right)-\mathrm{PPFA}$ 作为配体进行反应, 则新产生的两个季碳中心是不连续 的, 环加成的具有相反的区域选择性. 理论计算表明, $(S, S)$ - ${ }^{i} \operatorname{Pr}$-FOXAP 中的氮原子和磷原子在反应过程中一 直保持和铜的络合. 但是 $\left(S, R_{\mathrm{p}}\right)$-PPFA 中氮原子和铜的 络合在反应过程中有解离的过程. 这种机理上的差异导 致了区域选择性的不同. $\left[\mathrm{Cu}\left(\mathrm{CH}_{3} \mathrm{CN}\right)_{4}\right] \mathrm{BF}_{4} /\left(S, R_{p}\right)$-PPFA 体系 ${ }^{[39]}$ 同样适用于亚胺酯和 $\alpha$-三氟甲基取代的 $\alpha, \beta$-不饱 和酯的反应.

周智明等 ${ }^{[40]}$ 采用他们发展的 Si-FOXAP 配体, 以 $\left[\mathrm{Cu}\left(\mathrm{CH}_{3} \mathrm{CN}\right)_{4}\right] \mathrm{ClO}_{4}$ 作为催化剂, 实现了亚胺酯和三氟甲 基取代的硝基烯烃环加成反应. 反应在二氯甲烷中进 行, 所用碱为 $N, N$-二异丙基乙胺(DIPEA), 在 $10 \mathrm{~mol} \%$ 碱的存在下, 反应即能顺利进行, 最高可以获得大于 99\%的 $e e$ 值. 亚胺酯中苯基上取代基位置会影响反应的 对映选择性. 邻位取代的底物比间位和对位取代的底物 具有更好地选择性.

2017 年, 张俊良和刘媛媛等 ${ }^{[41]}$ 发现, 通过优化反应 条件, 可以通过亚胺酯和 $\beta$-三氟甲基取代的 $\alpha, \beta$-不饱和 酮的环加成反应来构建取代的 1-吡咯啉类化合物 (Scheme 20). 反应过程中少量水的存在对产物的选择 性至关重要. 当加入 6 equiv. 的水, 产物的 $e e$ 值可以达 到 $97 \%$. 控制实验表明, 反应可能经历一个分步的过程. 先发生 Michael 加成, 然后加成产物在室温下于盐酸中 处理得到产物.

2017 年, Merino 和 Pozo 等 ${ }^{[42]}$ 报道了有机小分子催 化的, 通过三氟甲基取代烯烃的 Michael 加成一分子内 $[3+2]$ 环加成的连续过程, 合成了四氢萗类化合物 (Scheme 21). 反应的非对映选择性较低, 但是对于每一 种非对映异构体, 其 ee 值很高, 最高可达到 $99 \%$. 使用
不同的亲核试剂可以获得不同的非对映选择性.

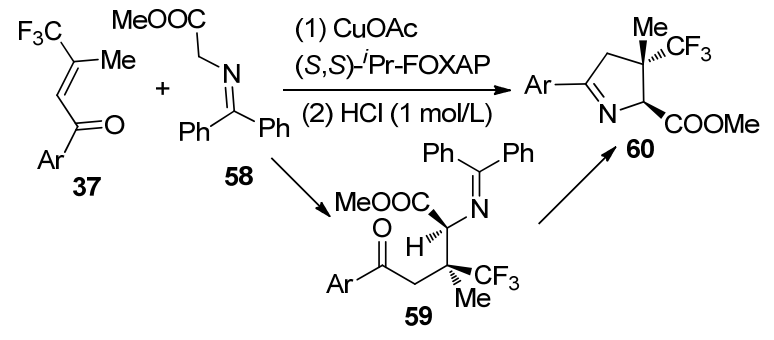

图式 $20[3+2]$ 环加成反应合成 1-吡咯啉类化合物 Scheme 20 Preparation of 1- pyrrolines via [3+2] cycloadditions

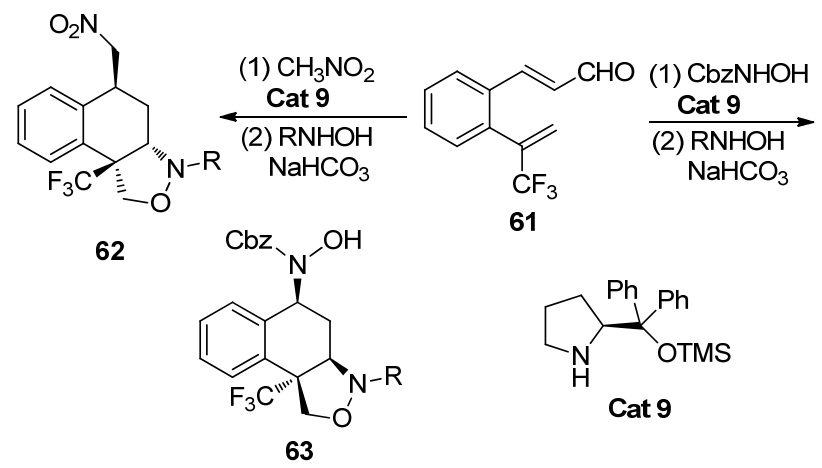

图式 21 连续的 Michael 加成-[3+2]环加成反应 Scheme 21 Sequential Michael addition-[3+2] cycloadditions

2.3.3 其他反应

金属催化的偶联反应在有机合成中得到了广泛应 用，但是三氟甲基取代烯烃的 Heck 反应报道较少. 2019 年, $\mathrm{Lu}$ 等 ${ }^{[43]}$ 报道了丙烯酰芳胺和末端炔烃在 $\mathrm{Pd} / \mathrm{Cu}$ 催化 下的 Heck-Sonogashira 偶联反应(Scheme 22), 可以中等 到优秀的收率和高 $e e$ 值得到含有一个三氟甲基季碳中 心的氧化吲哚类化合物. 该反应适用范围广泛，得到的 产物可以进一步衍生化.

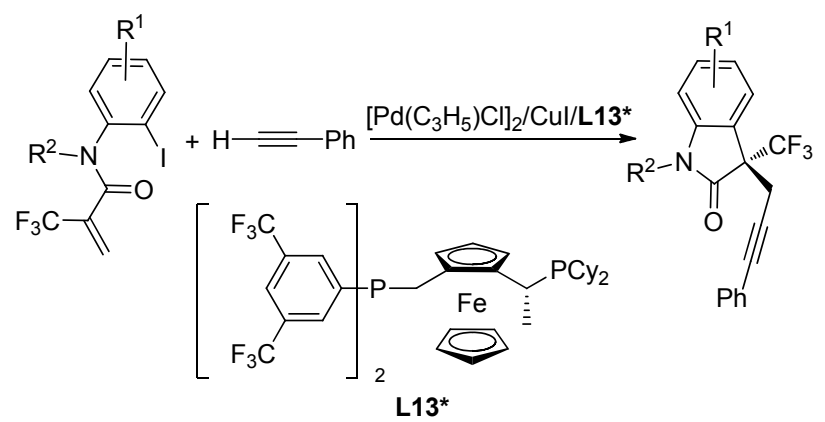

图式 $22 \mathrm{Pd} / \mathrm{Cu}$ 催化的 Heck-Sonogashira 偶联反应 Scheme $22 \mathrm{Pd} / \mathrm{Cu}$-catalyzed Heck-Sonogashira coupling reactions

三氟甲基取代的联烯也可以用来合成三氟甲基季 碳中心. 2013 年, Krische 等 ${ }^{[44]}$ 报道了钉催化的三氟甲基 取代联烯和甲醛的反应. 以 $\mathrm{RuHCl}(\mathrm{CO})\left(\mathrm{PPh}_{3}\right)_{3}$ 作为催化 
剂, dppm 作为配体, 在异丙醇存在下反应可以中等到良 好的收率得到含三氟甲基季碳中心的化合物. 作者推 测, 反应可能是由 $[\mathrm{Ru}-\mathrm{H}]$ 对联烯的加成引起的. 随后 甲酫对得到的烯丙基钓物种发生插入反应，进而从异丙 醇中夺取氢释放出产物. 2017 年, 该课题组 ${ }^{[45]}$ 对立体选 择性的铱催化的三氟甲基取代联烯和甲醇的反应进行 了研究, 在分子中同时引入一个氢原子和羟甲基. 采用 $[\operatorname{Ir}(\operatorname{cod}) \mathrm{Cl}]_{2}$ 或 $\operatorname{Ir}(\mathrm{cod})(\mathrm{acac})$ 作为催化剂, $(R)$-PhanePhos 作 为配体, 反应可以高收率、高选择性地得到手性的 $\beta$-三 氟甲基醇类化合物(Scheme 23). 该反应首先经历了甲 醇的脱氢过程, 得到一个 $[\mathrm{Ir}-\mathrm{H}]$ 物种, 然后联烯发生插 入反应得到的烯丙基铱物种和甲醛配位, 再反应得到产 物. 该反应底物适用范围广, 产物中的羟基可以进一步 转化, 为产物的转化利用提供了反应位点.

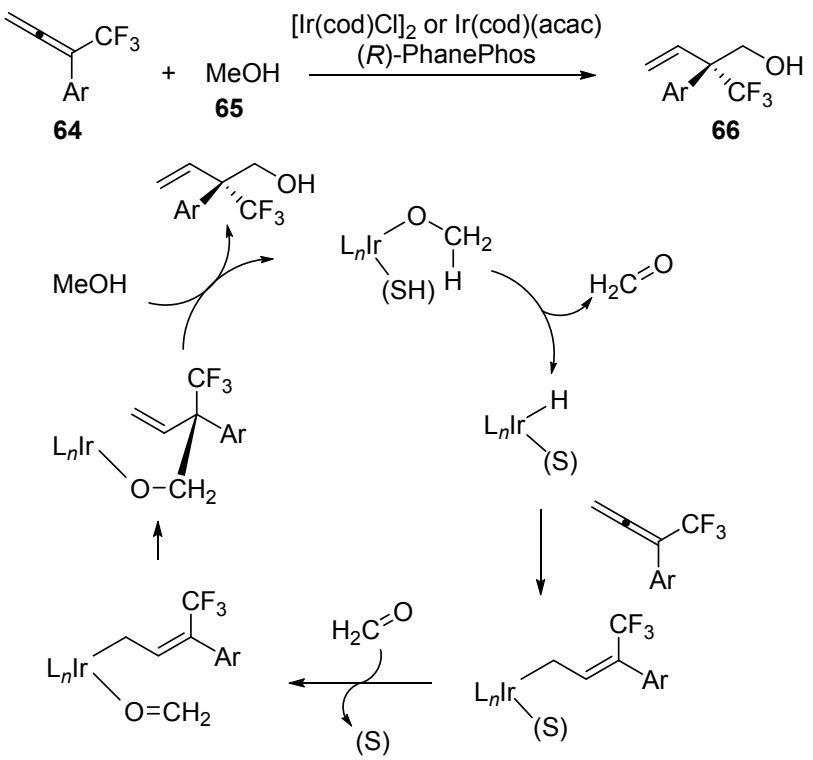

图式 23 铱催化的三氟甲基取代联烯的反应

Scheme 23 Ir-catalyzed reactions of trifluoromethylated allenes

\section{3 总结与展望}

含三氟甲基的化合物已经在农药和药物中得到了 广泛应用, 但是相对于 $\mathrm{C}_{\mathrm{sp}^{2}}-\mathrm{CF}_{3}$ 的形成, $\mathrm{C}_{\mathrm{sp}^{3}}-\mathrm{CF}_{3}$ 的构建 发展较为缓慢. 特别是三氟甲基季碳中心的构建更具有 挑战性，限制了具有该结构的化合物的应用. 近年来， 发展了不同的合成三氟甲基季碳中心的方法, 总结起来 主要有两种途径. 一是化合物直接三氟甲基化, 特别是 对叔碳原子直接三氟甲基化, 这是合成三氟甲基季碳中 心的简便方法. 酮、酯等化合物均可以发生反应，而且 可以得到较好的收率和对映选择性. 二是采用不同的含 三氟甲基的合成子，主要有三氟甲基取代的酯、三氟甲 基取代的叔澳代物、三氟甲基取代的烯烃等. 反应可以
是离子型的或自由基型的.

虽然现有的方法已经能够合成多种结构的含三氟 甲基季碳中心的化合物，但该领域仍然存在着一些挑 战. 在直接三氟甲基化方面, 所用的底物都需要有一个 吸电子基团活化 $\mathrm{C}-\mathrm{H}$, 非活化 $\mathrm{C}-\mathrm{H}$ 的直接三氟甲基 化反应几乎未见报道. 在利用三氟甲基合成子的反应 中, 合成子结构相对较少，主要是三氟甲基取代的烯烃， 所利用的反应主要是 Michael 加成, 包括许多环加成反 应，第一步也是由 Michael加成反应引发的. 因此，进一 步开发直接三氟甲基化反应，发展结构多样的三氟甲基 合成子和反应将仍是构建三氟甲基季碳中心的热点.

\section{References}

[1] For selected reviews, see: (a) Nie, J.; Guo, H.-C.; Cahard, D.; Ma, J.-A. Chem. Rev. 2011, 111, 455.

(b) Wang, J.; Sánchez-Roselló, M.; Aceña, J. L.; del Pozo, C.; Sorochinsky, A. E.; Fustero, S.; Soloshonok, V. A.; Liu, H. Chem. Rev. 2014, 114, 2432.

(c) Zhou, Y.; Wang, J.; Gu, Z.; Wang, S.; Zhu, W.; Aceña, J. L.; Soloshonok, V. A.; Izawa, K.; Liu, H. Chem. Rev. 2016, 116, 422.

(d) Chu, L.; Qing, F.-L. Acc. Chem. Res. 2014, 47, 1513.

(e) Tian, F.; Yan, G.; Yu, J. Chem. Commun. 2019, 55, 13486.

[2] For selected recent reviews, see: (a) Pierrot, D.; Merk, I. Angew. Chem., Int. Ed. 2020, 59, 36.

(b) Li, C.; Ragab, S.; Liu, G.; Tang, W. Nat. Prod. Rep. 2020, 37, 276.

(c) Feng, J.; Holmes, M.; Krische, M. J. Chem. Rev. 2017, 117, 12564 .

(d) Zeng, X.-P.; Cao, Z.-Y.; Wang, Y.-H.; Zhou, F.; Zhou, J. Chem. Rev. 2016, 116, 7330.

(e) Long, R.; Huang, J.; Gong, J.; Yang, Z. Nat. Prod. Rep. 2015, 32,1584 .

[3] Deng, Q.-H.; Wadepohl, H.; Gade, L. H. J. Am. Soc. Chem. 2012, 134, 10769.

[4] Granados, A.; Rivilla, I.; Cossío, F. P.; Vallribera, A. Chem.-Eur. J. 2019, 25, 8214.

[5] Katayev, D.; Matouśek, V.; Koller, R.; Togni, A. Org. Lett. 2015 , $17,5898$.

[6] Calvo, R.; Comas-Vives, A.; Togni, A.; Katayev, D. Angew. Chem., Int. Ed. 2019, 58, 1447.

[7] Früh, N.; Togni, A. Angew. Chem., Int. Ed. 2014, 53, 10813.

[8] Ye, J.-H.; Song, L.; Zhou, W.-J.; Ju, T.; Yin, Z.-B.; Yan, S.-S.; Zhang, Z.; Li, J.; Yu, D.-G. Angew. Chem., Int. Ed. 2016, 55, 10022.

[9] Woźniak, Ł.; Murphy, J. J.; Melchiorre, P. J. Am. Chem. Soc. 2015, 137,5678

[10] Matsui, H.; Murase, M.; Yajima, T. Org. Biomol. Chem. 2018, 16, 7120.

[11] Liu, Y.; Zhou, F.; He, K.; Cheng, T.; Zhong, Z.; Liu, Y.; Yang, Y. Phosphorus, Sulfur Silicon Relat. Elem. 2018, 193, 201.

[12] Guo, Y.; Zhao, X.; Zhang, D.; Murahashi, S.-I. Angew. Chem., Int. Ed. 2009, 48, 2047.

[13] Wang, Q.; Huan, F.; Shen, H.; Xiao, J.-C.; Gao, M.; Yang, X.; Murahashi, S.-I.; Chen, Q.-Y.; Guo Y. J. Org. Chem. 2013, 78, 12525.

[14] Foster, R. W.; Lenz, E. N.; Simpkins, N. S.; Stead, D. Chem.-Eur. J. 2017, 23, 8810 .

[15] (a) Li, L.; Huang, D.; Chen, Q.-Y.; Guo Y. Synlett 2013, 0611. (b) Li, L.; Chen, Q.-Y.; Guo, Y. Chem. Commun. 2013, 49, 8764.

[16] Wang, W., Huan, F.; Sun, Y.; Fang, J.; Liu, X.-Y.; Chen, Q.-Y.; Guo, Y. J. Fluorine Chem. 2015, 171, 46.

[17] Tian, P.; Wang, C.-Q.; Cai, S.-H.; Song, S.; Ye, L.; Feng, C.; Loh, T.-P. J. Am. Chem. Soc. 2016, 138, 15869.

[18] Huan, F.; Chen, Q.-Y.; Guo, Y. J. Org. Chem. 2016, 81, 7051. 
[19] Wang, W.; Guo, Y.; Sun, K.; Wang, S.; Zhang, S.; Liu, C.; Chen, Q.-Y. J. Org. Chem. 2018, 83, 14588.

[20] Kawai, H.; Okusu, S.; Tokunaga, E.; Sato, H.; Shiro, M.; Shibata, N. Angew. Chem., Int. Ed. 2012, 51, 4959.

[21] Kawai, H.; Yuan, Z.; Kitayama, T.; Tokunaga, E.; Shibata, N. Angew. Chem., Int. Ed. 2013, 52, 5575.

[22] Kwiatkowski, P.; Cholewiak, A.; Kasztelan, A. Org. Lett. 2014, 16, 5930.

[23] Sanz-Marco, A.; Blay, G.; Vila, C.; Pedro, J. R. Org. Lett. 2016, 18, 3538.

[24] Gao, J.-R.; Wu, H.; Xiang, B.; Yu, W.-B.; Han, L.; Jia, Y.-X. J. Am. Chem. Soc. 2013, 135, 2983.

[25] Ibáñez, I.; Kaneko, M.; Kamei, Y.; Tsutsumi, R.; Yamanaka, M.; Akiyama, T. ACS Catal. 2019, 9, 6903.

[26] Ma, C.-H.; Kang, T.-R.; He, L.; Liu, Q.-Z. Eur. J. Org. Chem. 2014, 3981.

[27] Chen, Q.; Wang, G.; Jiang, X.; Xu, Z.; Lin, L.; Wang, R. Org. Lett. 2014, 16, 1394.

[28] Sim, J.-H.; Park, J-H.; Maity, P.; Song, C.-E. Org. Lett. 2019, 21, 6715.

[29] Hou, X.; Ma, H.; Zhang, Z.; Xie, L.; Qin Z.; Fu, B. Chem. Commun. 2016, 52, 1470.

[30] (a) Hao, X.-Q.; Wang, C.; Liu, S.-L.; Wang, X.; Wang, L.; Gong, J.-F.; Song, M.-P. Org. Chem. Front. 2017, 4, 308.

(b) Lai, X.; Zha, G.; Liu, W.; Xu, Y.; Sun, P.; Xia, T.; Shen, Y. Synlett 2016, 27, 1983

[31] Nikolaev, V. A.; Supurgibekov, M. B.; Davies, H. M. L.; Sieler, J.; Zakharova, V. M. J. Org. Chem. 2013, 78, 4239.
[32] Loska, R.; Bukowsk, P. Org. Biomol. Chem. 2015, 13, 9872.

[33] Du, D.; Jiang, Y.; Xu, Q.; Tang, X.-Y.; Shi, M. ChemCatChem 2015, 7, 1366.

[34] Trost, B. M.; Debien, L. J. Am. Chem. Soc. 2015, 137, 11606.

[35] Zhang, Z.-M.; Xu, B.; Xu, S.; Wu, H.-H.; Zhang, J. Angew. Chem., Int. Ed. 2016, 55, 6324.

[36] Xu, B.; Zhang, Z.-M.; Xu, S.; Liu, B.; Xiao, Y.; Zhang, J. ACS Catal. 2017, 7, 210.

[37] Xu, B.; Zhang, Z.-M.; Liu, B.; Xu, S.; Zhou, L.-J.; Zhang, J. Chem. Commun. 2017, 53, 8152.

[38] Xu, S.; Zhang, Z.-M.; Xu, B.; Liu, B.; Liu, Y.; Zhang, J. J. Am. Chem. Soc. 2018, 140, 2272.

[39] Xu, S.; Liu, B.; Zhang, Z.-M.; Xu, B.; Zhang, J. Chin. J. Chem. 2018, 36, 421.

[40] Tang, L.-W.; Zhao, B.-J.; Dai, L.; Zhang, M.; Zhou, Z.-M. Chem.-Asian J. 2016, 11, 2470.

[41] Liu, B.; Zhang, Z.-M.; Xu, B.; Xu, S.; Wu, H.-H.; Liu Y.; Zhang, J. Org. Chem. Front. 2017, 4, 1772.

[42] Rabasa-Alcañiz, F.; Torres, J.; Sánchez-Roselló, M.; Tejero, T.; Merino, P.; Fustero, S.; del Pozo, C. Adv. Synth. Catal. 2017, 359, 3752 .

[43] Bai, X.; Wu, C.; Ge, S.; Lu, Y. Angew. Chem., Int. Ed. 2020, 59, 2764.

[44] Sam, B.; Montgomery, T. P.; Krische, M. J. Org. Lett. 2013, 15, 3790 .

[45] Holmes, M.; Nguyen, K. D.; Schwartz, L. A.; Luong, T.; Krische, M. J. J. Am. Chem. Soc. 2017, 139, 8114. 